\title{
Tannic acid synergistically enhances the anticancer efficacy of cisplatin on liver cancer cells through mitochondria-mediated apoptosis
}

\author{
NANA GENG ${ }^{1,2}$, XIANG ZHENG $^{3}$, MINGSONG WU $^{1}$, LEI YANG $^{3}, \mathrm{XUEYING} \mathrm{LI}^{3}$ and JINDONG CHEN ${ }^{3,4}$ \\ ${ }^{1}$ Special Key Laboratory of Oral Disease Research, and ${ }^{2}$ Special Key Laboratory of Microbial Resources and \\ Drug Development, Higher Education Institution in Guizhou Province; ${ }^{3}$ Department of Medical Genetics, \\ Zunyi Medical University, Zunyi, Guizhou 563006, P.R. China; ${ }^{4}$ Department of Urology, \\ University of Rochester Medical Center, Rochester, NY 14642, USA
}

Received February 6, 2019; Accepted July 12, 2019

DOI: 10.3892/or.2019.7281

\begin{abstract}
Cisplatin (cis-dichlorodiamine platinum, CDDP) is a potent antitumor agent. However, its clinical application is limited by its side effects and the development of drug resistance. Tannic acid (TA) has previously been reported to suppress tumor growth in different types of cancer. The present study evaluated the anticancer efficacy of TA in combination with CDDP on the liver cancer cell line HepG2, and investigated the associated underlying molecular mechanisms. The results revealed that treatment with TA or CDDP alone inhibited HepG2 cell growth, with a half maximal inhibitory concentration of $360 \mu \mathrm{M}$ and $1.8 \mu \mathrm{g} / \mathrm{ml}$, respectively. The combination of TA and CDDP induced mitochondria-mediated apoptosis in HepG2 cells and significantly enhanced the growth inhibitory effect compared with TA or CDDP treatment alone. The results obtained from the present study suggest that the combination of TA and CDDP may exert synergistic anticancer effects and may be a novel adjuvant treatment for liver cancer.
\end{abstract}

\section{Introduction}

Liver cancer is the sixth most common cancer worldwide, accounting for $5.6 \%$ of the total cases diagnosed in 2012 (1-4).

Correspondence to: Professor Xueying Li or Professor Jindong Chen, Department of Medical Genetics, Zunyi Medical University, 6 Xuefu West Road, Zunyi, Guizhou 563006, P.R. China

E-mail: leexueying4722@163.com

E- mail: jindong_chen@hotmail.com

Abbreviations: CDDP, cis-dichlorodiamine platinum; TA, tannic acid; MTP, mitochondrial transmembrane potential; CI, combination index; DRI, dose reduction index; CytC, cytochrome $c$

Key words: tannic acid, cis-dichlorodiamine platinum, cisplatin, liver cancer, mitochondria-mediated apoptosis
Liver cancer accounted for $9.1 \%$ of cancer-associated deaths in 2012. In developed countries, liver cancer is the sixth leading cause of cancer-associated mortality among men. In 2012, an estimated 782,000 new liver cancer cases and 745,000 deaths occurred globally, with $>50 \%$ of the total cases and deaths reported in China (2-5). In China, liver cancer is the fourth most common cancer and the third leading cause of cancer-associated mortality (5). Late diagnosis and low efficacy of pharmacotherapeutics account for the high mortality rate of liver cancer (1). Cisplatin (cis-dichlorodiamine platinum, CDDP) is one of the most effective and commonly used chemotherapeutic drugs for the treatment of certain advanced carcinomas. CDDP has been used alone or in combination with other agents to treat different types of cancer (6). Previous studies have reported that CDDP combination chemotherapy decreased the development of drug resistance in laryngeal cancer, and improved the survival rate of the patients (6-9). However, the use of CDDP alone may result in the development of tolerance; this would require the use of higher doses to achieve the desired efficacy, leading to toxic side effects and poor patient outcome (10-12). In order to overcome this limitation, CDDP has been used in combination with other anticancer drugs for the treatment of laryngeal cancer $(6,7,9,13,14)$. Furthermore, CDDP is one of the most commonly used chemotherapeutic agents for the treatment of $\mathrm{HCC}$, although its efficacy is limited by its toxic side effects. Additionally, liver cancer is resistant to chemotherapy, which complicates the treatment of the disease $(15,16)$. There is therefore a requirement for adjuvant drugs to limit the side effects of CDDP.

Tannic acid (TA), a natural plant polyphenol, has been widely used as a dietary supplement in the pharmaceutical industry (17). TA inhibits cell growth in various types of cancer, including breast, prostate, skin, ovarian and gingival cancer, colorectal carcinoma, cholangiocarcinoma, glioma and leukemia (17-32). TA exhibits low toxicity to healthy cells and may be administered orally (17). A previous study revealed that a combination of TA and CDDP induced apoptosis in ovarian cancer cells (17). The aim of the present study was to investigate whether the combination of TA and CDDP therapy 
successfully inhibits liver cancer cell growth and whether the underlying mechanism involves mitochondria-mediated apoptosis.

\section{Materials and methods}

Cell culture. The human liver cancer cell line HepG2 was purchased from the American Type Culture Collection and maintained in RPMI-1640 (Gibco; Thermo Fisher Scientific, Inc.) supplemented with $10 \%$ fetal bovine serum (FBS; Zhejiang Tian Hang Biological Science and Technology Co., Ltd.), $2.0 \mathrm{~g} / 1$ sodium hydrogen carbonate, $100 \mu \mathrm{g} / \mathrm{ml}$ streptomycin and $100 \mathrm{U} / \mathrm{ml}$ penicillin. The cells were maintained in an incubator at $37^{\circ} \mathrm{C}\left(5 \% \mathrm{CO}_{2}\right)$, and experiments were conducted during the exponential growth phase. However, the cell line was not authenticated in our laboratory since it was purchased in 2013.

Cell viability assay. HepG2 cells were cultured in RPMI-1640 supplemented with $10 \%$ FBS for $24 \mathrm{~h}$. The cells were then treated with TA (Cell Signaling Technology, Inc.) at 0, 90, 180, 270, 360, 450 and $540 \mu \mathrm{M}$, and CDDP (Qilu Pharmaceutical Co., Ltd.) at $0,0.6,1.2,1.8,2.4,3.0$ and $3.6 \mu \mathrm{g} / \mathrm{ml}$ for $24 \mathrm{~h}$. Subsequently, the cells were subjected to MTT analysis according to the manufacturer's protocol (Solar Biotechnology Co., Ltd.). The cell inhibition rate was calculated as follows: 1-(drug A value-control A value)/inhibition rate $(\%)=1$-(drug A value-control A value)/(control A value-blank A value).

Measurement of the combination index (CI) and dose reduction index (DRI). The effect of drug synergism on cancer cells may be determined using CI and DRI. In the present study, the synergistic effect of TA and CDDP was determined using the following formula:

$$
\begin{gathered}
\mathrm{CI}=(\mathrm{D}) 1 /(\mathrm{Dx}) 1+(\mathrm{D}) 2 /(\mathrm{Dx}) 2 \\
(\mathrm{DRI}) 1=(\mathrm{Dx}) 1 /(\mathrm{D}) 1,(\mathrm{DRI}) 2=(\mathrm{Dx}) 2 /(\mathrm{D}) 2,
\end{gathered}
$$

where $(\mathrm{Dx}) 1=$ dose of drug 1 required to produce $50 \%$ cell death; (D) $1=$ dose of drug 1 required to produce $50 \%$ cell death in combination with (D)2; (Dx)2 $=$ dose of drug 2 required to produce $50 \%$ cell death; (D) $2=$ dose of drug 2 required to produce $50 \%$ cell death in combination with (D) 1 . CI $<1$ indicates a synergistic effect of the two drugs, $\mathrm{CI}=1$ suggests an additive effect and CI $>1$ indicates antagonism.

The DRI estimates to what extent the dose of one or more drugs in a synergistic combination may be reduced to achieve effects that are comparable with those achieved with each drug alone. The inverted terms in the CI equation are the DRIs for the corresponding individual drugs in combination. The reduced dose of each drug reduces toxicity and the increased effect in combination leads to beneficial clinical outcomes.

Changes in cell and nuclear morphology. A total of $3 \times 10^{5}$ HepG2 cells were plated into each well of a 6-well plate and incubated for $24 \mathrm{~h}$. A total of four treatment groups were created: i) cells exposed to $180 \mu \mathrm{M} \mathrm{TA}+0.9 \mu \mathrm{g} / \mathrm{ml}$ CDDP; ii) cells exposed to $180 \mu \mathrm{M} \mathrm{TA}$; iii) cells exposed to $0.9 \mu \mathrm{g} / \mathrm{ml}$
CDDP; and iv) cells exposed to a saline control. The cells were incubated for a further $24 \mathrm{~h}$ prior to morphological analysis. For nuclear morphological analysis, the cells were fixed with acetone, stained with DAPI for $5 \mathrm{~min}$, and examined using a fluorescence microscope (cat. no. IX73; Olympus Corporation).

Annexin V-fluorescein isothiocyanate (FITC)/propidium iodide (PI) apoptosis assay. HepG2 cells were collected in an Eppendorf tube, washed twice with PBS, centrifuged at $800 \mathrm{x} \mathrm{g}$ for $5 \mathrm{~min}$ at $4^{\circ} \mathrm{C}$, and resuspended in calcium-enriched HEPES buffer. The cells were then subjected to Annexin V-FITC/PI apoptosis analysis according to the manufacturer's instructions (BBI Co., Ltd.). Briefly, the cells were stained with Annexin V-FITC and PI for 15 min and analyzed using a flow cytometer (Gallios; Beckman Coulter) with FlowJo software (version 7.6.3; Tree Star, Inc.).

Mitochondrial transmembrane potential (MTP). Cells were washed twice with PBS and centrifuged at $800 \mathrm{xg}$ for $5 \mathrm{~min}$. The cells were then stained using JC-1 (cat. no. C2006; Beyotime Institute of Biotechnology) and the MTP was determined according to the manufacturer's protocol (Beyotime Institute of Biotechnology). Cells were then analyzed using a flow cytometer.

Reverse transcription-quantitative polymerase chain reaction $(R T-q P C R)$ analysis. Total RNA was extracted from HepG2 cells and reverse-transcribed into cDNA. M-MLV reverse transcriptase and RNase inhibitor were purchased from Promega Corporation, and dNTP mix (10 mM) was purchased from Shanghai Bio-Tech Co., Ltd. RNAiso ${ }^{\mathrm{TM}}$ Plus was purchased from Takara Bio Inc. cDNA was used at a 1:10 dilution for qPCR. The primers for qPCR were as follows: $\beta$-actin forward, 5'-CGGGAAATCGTGCGTGAC-3' and reverse, 5'-CAGGAA GGAAGGCTGGAAG-3'; Bcl-2 forward, 5'-GGTGGGGTC ATGTGTGTGG-3' and reverse, 5'-CGGTTCAGGTACTCA GTCATCC-3'; Bcl-2-associated X apoptosis (Bax) forward, 5'-CCCGAGAGGTCTTTTTCCGAG-3' and reverse, 5'-CCA GCCCATGATGGTTCTGAT-3'; and cytochrome $c$ (CytC) forward, 5'-CTTTGGGCGGAAGACAGGTC-3', and reverse, 5'-TTATTGGCGGCTGTGTAAGAG-3'. The qPCR reaction mixture consisted of $1 \mu \mathrm{l}$ cDNA, $5 \mu 1 \mathrm{SsoFast}^{\mathrm{TM}}$ EvaGreen $^{\circledR}$ Supermix (Bio-Rad Laboratories, Inc.), $0.5 \mu 1$ of each primer and $3.5 \mu \mathrm{l}$ distilled water. The thermocycling conditions were as follows: Initial denaturation at $94^{\circ} \mathrm{C}$ for $60 \mathrm{sec}$, followed by 40 cycles at $95^{\circ} \mathrm{C}$ for $20 \mathrm{sec}$ and at $56^{\circ} \mathrm{C}$ (for $\beta$-actin and Bax), $60.3^{\circ} \mathrm{C}$ (for $\mathrm{Bcl}-2$ ), or $57.6^{\circ} \mathrm{C}$ (for $\mathrm{CytC}$ ) for $30 \mathrm{sec}$. The mRNA levels were quantified using the $2^{-\Delta \Delta \mathrm{Cq}}$ method (33) and normalized to the internal reference gene $\beta$-actin. qPCR experiments were performed in triplicate.

Western blotting. HepG2 cells were collected and lysed using RIPA lysis buffer. Total protein was quantified using the bicinchoninic acid assay and $20 \mu \mathrm{g}$ protein/lane was separated by SDS-PAGE on a $10 \%$ gel. The separated proteins were subsequently transferred to a polyvinylidene fluoride membrane (Merck KGaA). The membrane was washed and blocked using TBS $/ 0.1 \%$ Tween-20 (TBST) solution with $5 \%$ non-fat dry milk for $1 \mathrm{~h}$ at room temperature. Primary 
Table I. Combination index (CI) and dose reduction index (DRI) for the drug combination of TA and CDDP.

\begin{tabular}{|c|c|c|c|c|c|c|c|}
\hline \multirow[b]{2}{*}{ Growth inhibition rate (\%) } & \multirow[b]{2}{*}{ CI } & \multicolumn{2}{|c|}{$\mathrm{TA}(\mu \mathrm{M})$} & \multirow[b]{2}{*}{ DRI } & \multicolumn{2}{|c|}{$\operatorname{CDDP}(\mu \mathrm{g} / \mathrm{ml})$} & \multirow[b]{2}{*}{ DRI } \\
\hline & & Single & Combined & & Single & Combined & \\
\hline 9 & 0.44 & 90 & 22.5 & 4.0 & 0.6 & 0.1125 & 5.3 \\
\hline 22 & 0.48 & 180 & 45 & 4.0 & 1.0 & 0.225 & 4.4 \\
\hline 32 & 0.70 & 240 & 90 & 2.7 & 1.4 & 0.45 & 3.1 \\
\hline 61 & 0.75 & 450 & 180 & 2.5 & 2.6 & 0.9 & 2.9 \\
\hline 70 & 1.35 & 510 & 360 & 1.4 & 2.8 & 1.8 & 1.6 \\
\hline
\end{tabular}

TA, tannic acid; CDDP, cis-dichlorodiamine platinum.

antibodies against Bcl-2 (1:1,000; cat. no. 12789-1-AP; ProteinTech Group, Inc.), Bax (1:2,000; cat. no. 50599-2-Ig, ProteinTech Group, Inc.), CytC (1:10,000; Abcam) and $\beta$-actin (1:10,000; cat. no. 60008-1-Ig, ProteinTech Group, Inc.) were diluted in TBST/3\% bovine serum albumin (cat. no. 9048-46-8, Sigma-Aldrich; Merck KGaA) and incubated with the membrane at room temperature for $1 \mathrm{~h}$. Following primary antibody incubation, the membrane was washed and incubated with a goat anti-mouse secondary antibody (dilution: 1:1,000; cat. no. sc-2039; Santa Cruz Biotechnology, Inc.) for $1 \mathrm{~h}$ at room temperature. Protein bands were visualized using a Gel Doc XR imaging system (Bio-Rad Laboratories, Inc.) and analyzed using Quantity One image analysis software (version 4.62; Bio-Rad Laboratories, Inc.). IPP software was used for protein band grey scale measurement.

Statistical analysis. The data were analyzed using SPSS software (version 22.0; IBM Corp.). One-way analysis of variance followed by the Student-Newman-Keuls post hoc test was used to evaluate the differences between the treatment groups. The synergistic effect of TA and CDDP may be predicted using an isobologram, a graph constructed on a coordinate system composed of the individual drug doses. The graph commonly contains a straight line of additivity, the isobol, that is constructed based on the maximum additive efficacy of two drugs, and is employed to distinguish additive from synergistic and antagonistic interactions (34). When the observed data points predominantly fell on the left- or right-hand side of the isobol, the combinations were considered to have a synergistic and antagonistic effect, respectively. Combinations with $\mathrm{P}>0.05$ indicated additive to synergistic (or additive to antagonistic) effects. The results are presented as mean \pm standard deviation, and $\mathrm{P}<0.05$ was considered to indicate statistically significant differences.

\section{Results}

Combined TA and CDDP treatment suppresses HepG2 cell viability and affects cell morphology. The MTT assay was performed to investigate the effect of treatment with TA or CDDP on the viability of HepG2 cells. The results demonstrated that both TA and CDDP significantly decreased cell viability $(\mathrm{P}<0.01)$. The inhibition was dose-dependent and the half maximal inhibitory concentration $\left(\mathrm{IC}_{50}\right)$ values were $360 \mu \mathrm{M}$ and $1.8 \mu \mathrm{g} / \mathrm{ml}$, respectively (Fig. 1A and B).

The synergistic effect of drugs may be determined using $\mathrm{CI}$ and DRI. In the present study, the combined inhibition rate of TA and CDDP dose-dependently increased from 9 to $70 \%$, and the corresponding CIs were $0.44,0.48,0.70$, 0.75 and 1.35 , respectively. This suggests that the combined use of TA and CDDP exerted a synergistic effect on HepG2 cells. The dose ratios of TA and CDDP fell within a range of 1.4-4.0 and 1.6-5.3, respectively (Table I). The required doses of TA and CDDP were markedly decreased when the two drugs were used in combination (Table I).

HepG2 cells were exposed to a combination of TA and CDDP at their respective half $\mathrm{IC}_{50}$ values (TA, $180 \mu \mathrm{M}$; CDDP, $0.9 \mu \mathrm{g} / \mathrm{ml}$ ). While the individual inhibition rate was $19.1 \pm 6.0 \%$ for TA and $17.5 \pm 4.0 \%$ for CDDP, the combined inhibition rate increased up to $60.3 \pm 2.0 \%$. Further statistical analysis indicated that the combined inhibition rate was significantly increased compared with that of TA or CDDP alone $(\mathrm{P}<0.01$; Fig. $1 \mathrm{C}$ and $\mathrm{D})$.

In the present study, the majority of the dose ratio points for TA and CDDP were on the left side of the isobol (Fig. 1E), indicating that TA and CDDP exerted synergistic effects on HepG2 cells.

$T A$ and CDDP synergistically increase apoptosis in HepG2 cells. Control cells appeared morphologically normal. The cells were spindle- or polygonal-shaped in nature, had clear boundaries and had a homogenous cell refractive index. Additionally, all cells were attached to the bottom of the dish. By contrast, a large proportion of cells exposed to TA or CDDP for $24 \mathrm{~h}$ had detached, shrunk, become rounded and had a low refractive index. Furthermore, cells exposed to a combination of TA and CDDP for $24 \mathrm{~h}$ had detached and died, and the cell fragments had a very low refractive index (Fig. 2A).

Additionally, DAPI staining revealed that the nuclei of the control cells appeared light blue in color, were round or oval-shaped, and had a homogenous distribution of chromatin. A proportion of the nuclei of TA- or CDDP-treated cells appeared condensed and dark blue. In HepG2 cells treated with a combination of TA and CDDP, several nuclei were fragmented, and the cells had split into apoptotic bodies of various sizes (Fig. 2B, arrows), which represent the typical morphological characteristics of apoptosis. 
A

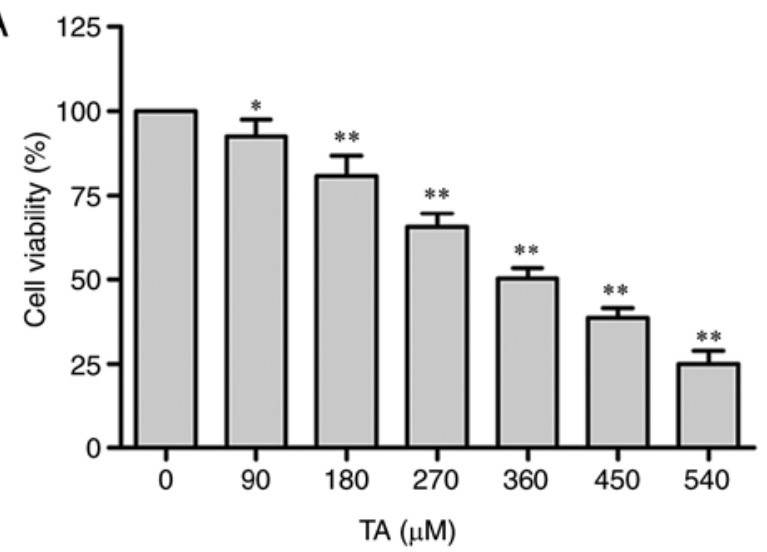

C

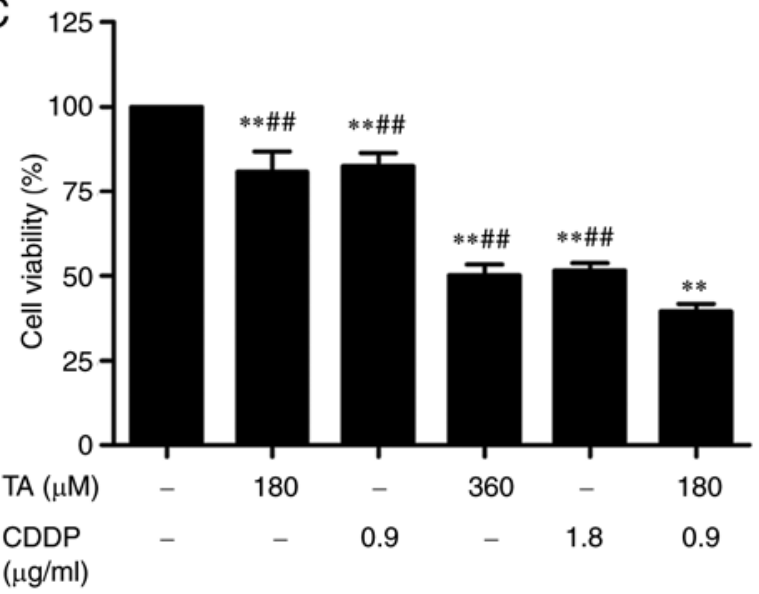

B

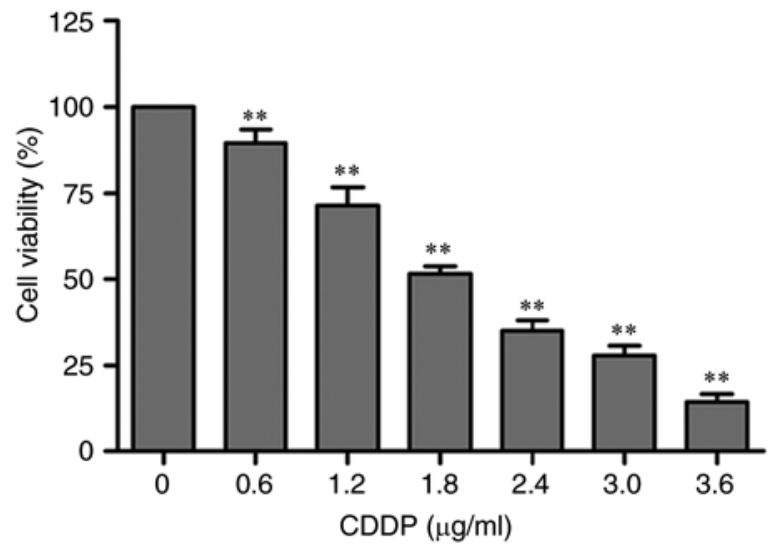

D

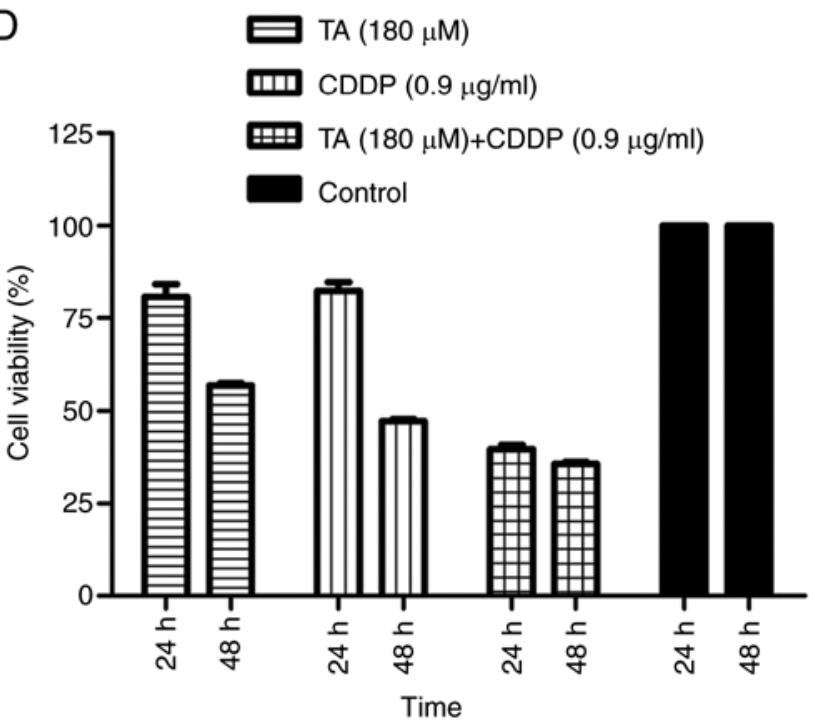

E Normalized isobologram

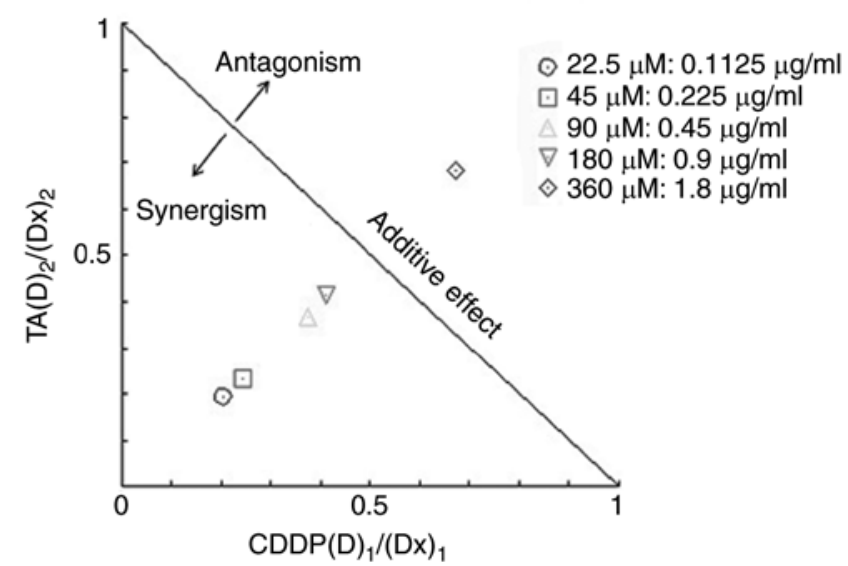

Figure 1. TA and CDDP inhibit HepG2 cell growth in vitro. HepG2 cells were treated with TA, CDDP and TA + CDDP for 24 or $48 \mathrm{~h}$. MTT analysis indicated that (A) TA and (B) CDDP alone inhibited HepG2 cell growth in a dose-dependent manner after $24 \mathrm{~h}$. A combination of TA and CDDP synergistically inhibited cell growth at (C) 24 and (D) $48 \mathrm{~h}$. (E) Isobologram analysis of the cytotoxicity of TA and CDDP treatment alone or in combination. The diagonal line represents the isoeffect line of additivity. Points above this line indicate antagonism between drugs, and points below this line indicate synergy. Experiments were performed in triplicate. ${ }^{*} \mathrm{P}<0.05$ and ${ }^{* *} \mathrm{P}<0.01$, untreated control group vs. the TA- or CDDP-treated group, respectively; ${ }^{\# \#} \mathrm{P}<0.01$, the TA- or CDDP-treated group vs. the TA + CDDP group. TA, tannic acid; CDDP, cis-dichlorodiamine platinum.

To further verify that TA and CDDP synergistically increase the apoptosis of HepG2 cells, Annexin V-FITC/PI analysis was performed to detect cells in the early and late stages of apoptosis. The results indicated that the cells exposed to a combination of TA and CDDP for $24 \mathrm{~h}$ exhibited the highest percentage of apoptosis $(20.9 \pm 2 \%)$, while the control, TA and CDDP groups exhibited apoptotic percentages of $2.6 \pm 0.2,4.8 \pm 0.5$ and $4.6 \pm 0.8 \%$, respectively. The apoptotic rates in the three treatment groups were significantly higher compared with the control group $(\mathrm{P}<0.01)$. Furthermore, the 
A
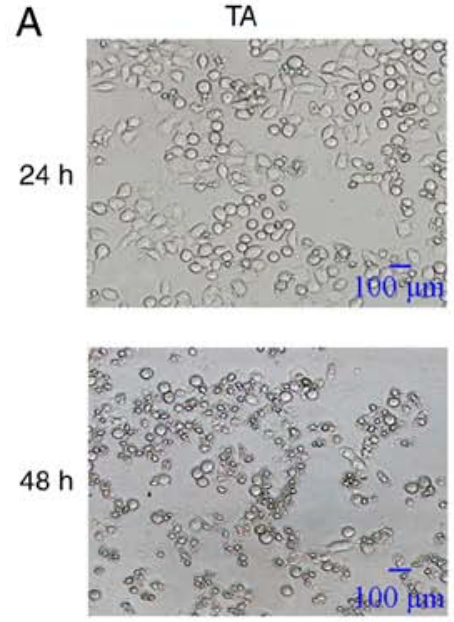

B
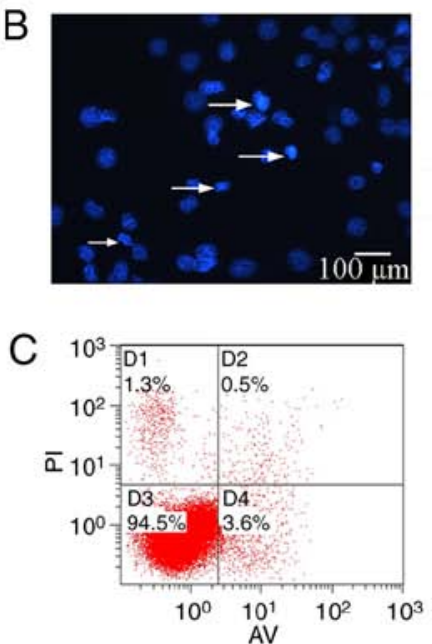
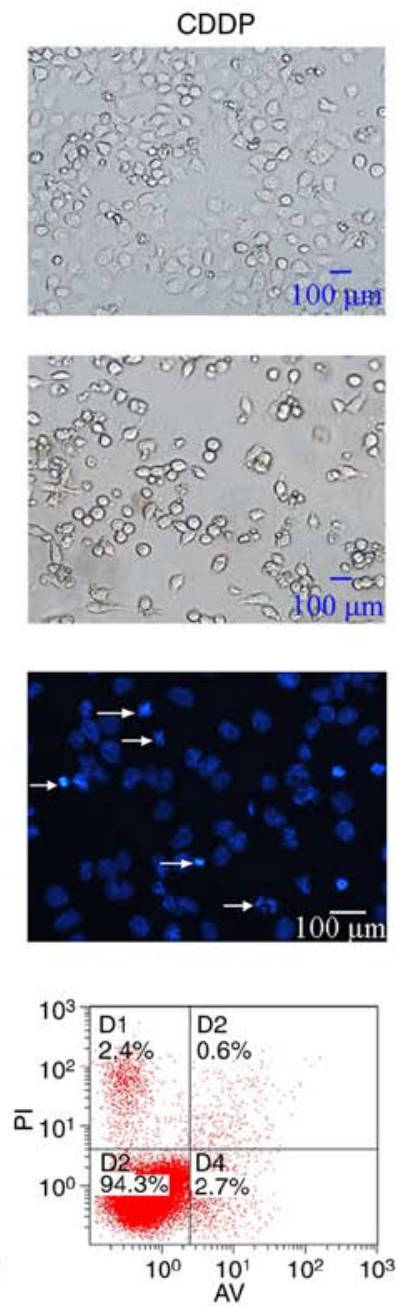
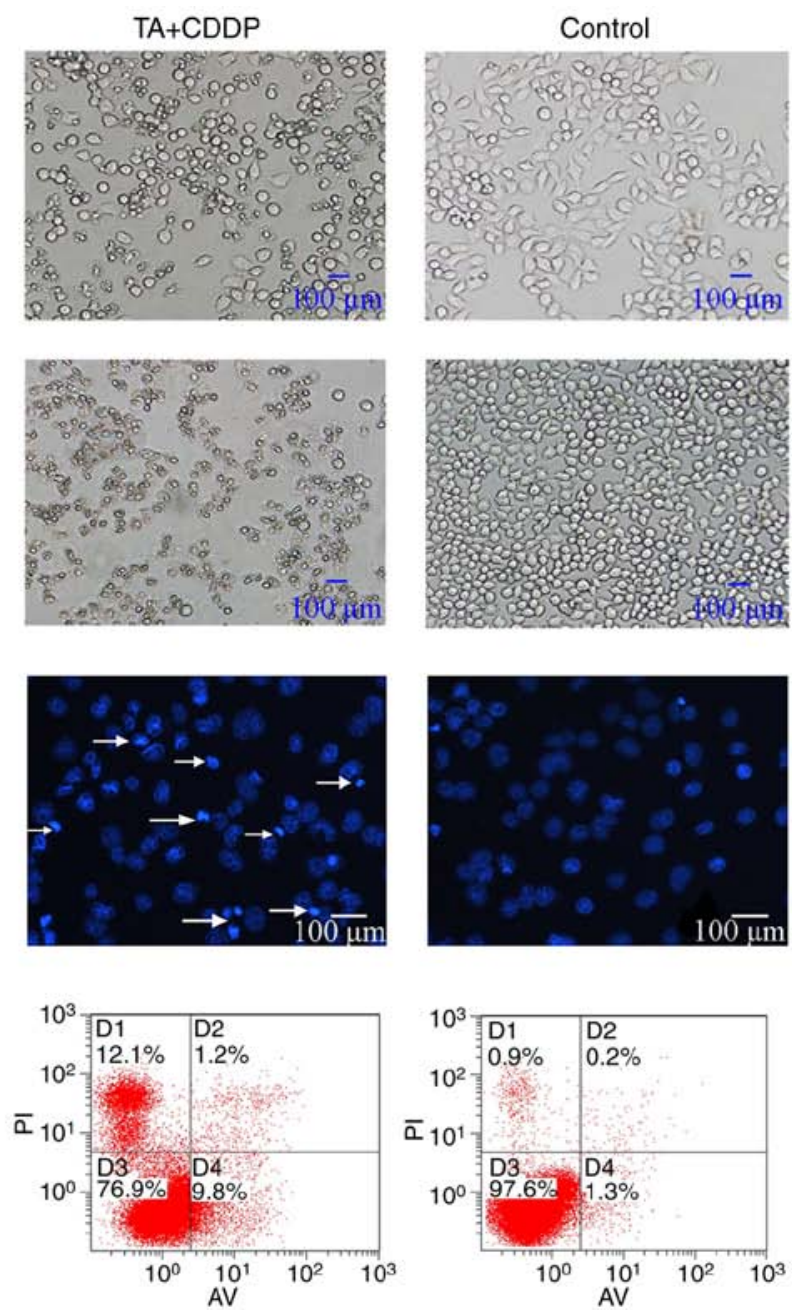

Figure 2. Combination treatment with TA and CDDP results in cellular and nuclear morphological changes and induces apoptosis in HepG2 cells. (A) Cell morphology observed under an optical microscope following treatment with TA or/and CDDP for 24 and 48 h. (B) Nuclei were stained using DAPI, and apoptotic bodies or nuclear fragments (arrows) were observed under a fluorescence microscope (magnification, x400) following treatment with TA and/or CDDP for $24 \mathrm{~h}$. (C) Flow cytometric analysis indicating the percentages of necrotic, late apoptotic, living and early apoptotic cells (represented by quadrants D1, D2, D3 and D4, respectively) following treatment with TA and/or CDDP for $24 \mathrm{~h}$. TA, tannic acid; CDDP, cis-dichlorodiamine platinum.

apoptotic rate of the TA + CDDP group was significantly higher compared with that of any of the other groups $(\mathrm{P}<0.01$; Fig. 2C).

Combination treatment with TA and CDDP activates mitochondria-mediated apoptosis. To determine whether TA and CDDP synergistically promoted mitochondrial-induced apoptosis, an MTP assay was performed using a JC-1 kit. JC-1 accumulates in mitochondria in a membrane potential-dependent manner, which may be detected by a fluorescence emission shift from green $(\sim 529 \mathrm{~nm})$ to red $(\sim 590 \mathrm{~nm})$. Mitochondrial depolarization is determined based on the decrease in the red/green fluorescence intensity ratio. Therefore, the JC-1 fluorescent dye may be used as an indicator of MTP in cells. The shift of JC-1 fluorescence from red to green represents early apoptosis. In the present study, the MTP declining rate for the control group was $1.7 \pm 0.3 \%$, and the declining rates for the TA, CDDP and TA + CDDP groups following $24 \mathrm{~h}$ of treatment were $6.2 \pm 2.0,4.3 \pm 0.3$ and $24.2 \pm 0.5 \%$, respectively. The MTP declining rate in the three treatment groups was significantly higher compared with that in the control group $(\mathrm{P}<0.01)$, and the MTP declining rate of the TA + CDDP group was significantly higher compared with that in the TA or CDDP alone groups $(\mathrm{P}<0.01)$. These results further demonstrated that a combination of TA and CDDP synergistically increased early apoptotic events in HepG2 cells (Fig. 3).

To determine whether the mitochondrial-induced apoptotic pathway in HepG 2 cells was activated by TA and CDDP, the expression of apoptosis-associated genes was investigated by RT-qPCR analysis and western blotting. The results revealed that $\mathrm{Bcl}-2$ expression was downregulated, while $\mathrm{Bcl}-2$ expression was upregulated following exposure to a combination of TA + CDDP for $48 \mathrm{~h}$ (Figs. 4A, 5A and B). Furthermore, Bax (Figs. 4B, 5A and C), CytC (Figs. 4C, 5A and D), caspase-3 and cleaved caspase-3 were upregulated, while procaspase-3 was downregulated (Figs. 4D and 5A, E and F).

In addition, the combination of TA and CDDP promoted the release of $\mathrm{CytC}$ from the mitochondria into the cytoplasm, while a proportion of Bax translocated from the cytoplasm into the mitochondria (Fig. 6A-C). These data suggested that TA + CDDP treatment induced apoptosis through a mitochondria-mediated signaling pathway. 

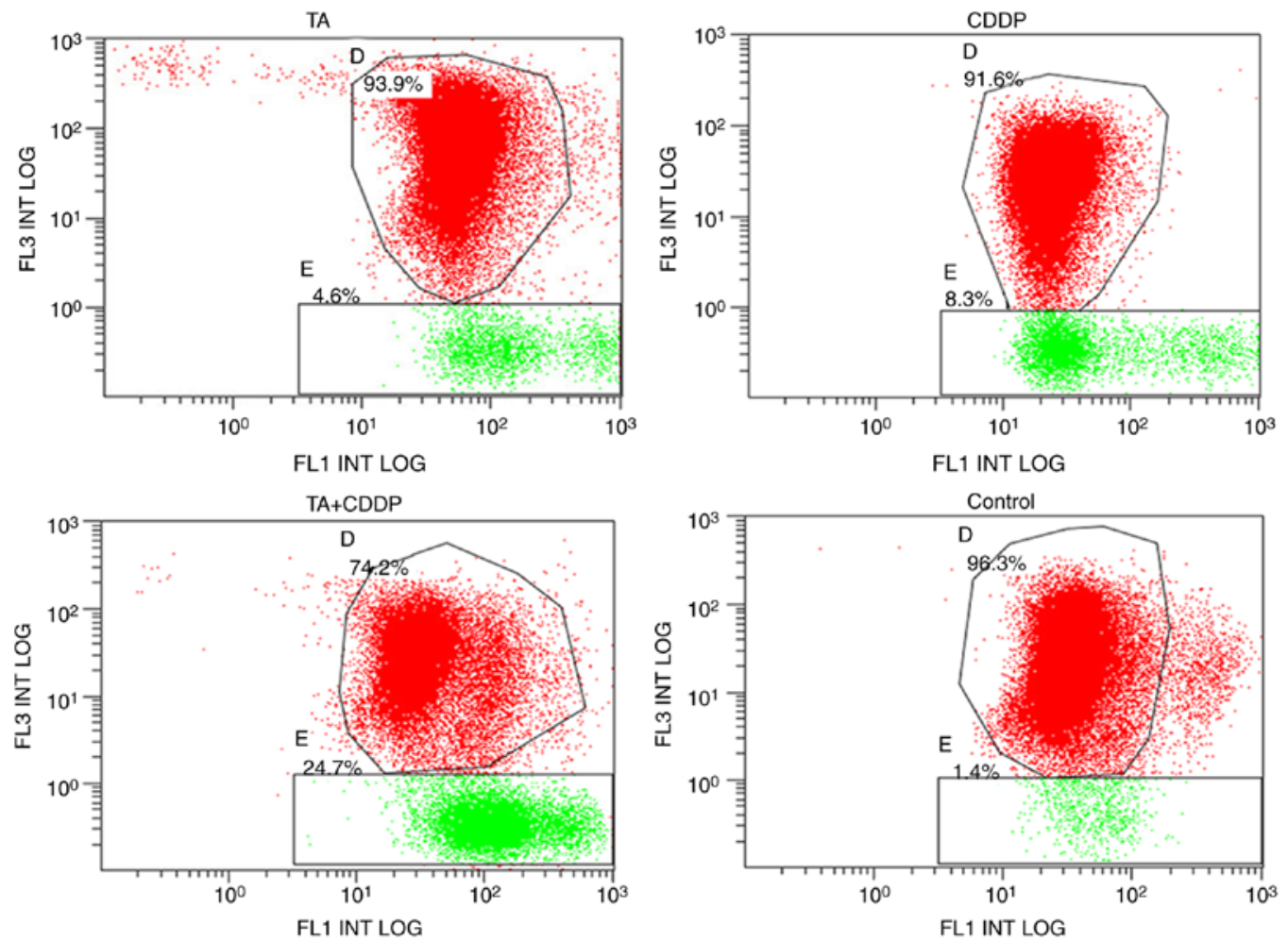

Figure 3. Flow cytometry revealed that the combination of TA and CDDP increases MTP. Cells were exposed to a combination of TA and CDDP for $24 \mathrm{~h}$ and the MTP was tested using the JC-1 assay and flow cytometry. The MTP declining rate in all treatment groups was significantly higher compared with that in the control group $(\mathrm{P}<0.01)$. The MTP declining rate of the TA + CDDP group was significantly higher compared with that of the TA or CDDP groups $(\mathrm{P}<0.01)$. Experiments were performed in triplicate. TA, tannic acid; CDDP, cis-dichlorodiamine platinum; MTP, mitochondrial transmembrane potential.

A

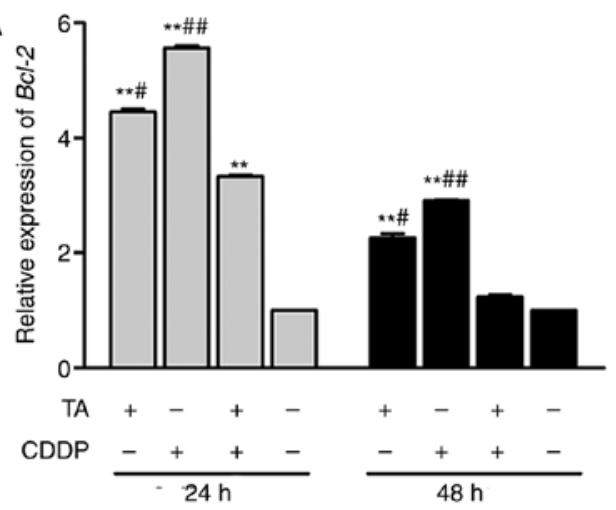

C

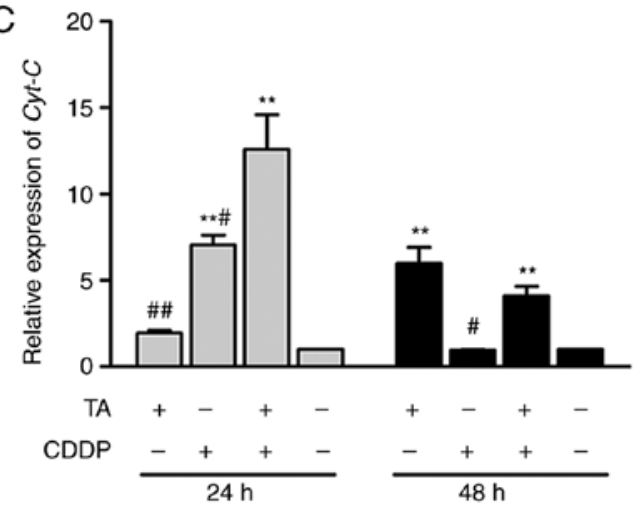

B

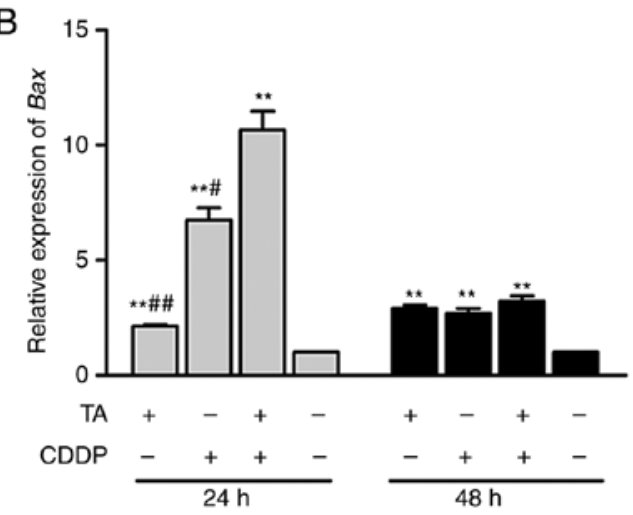

D

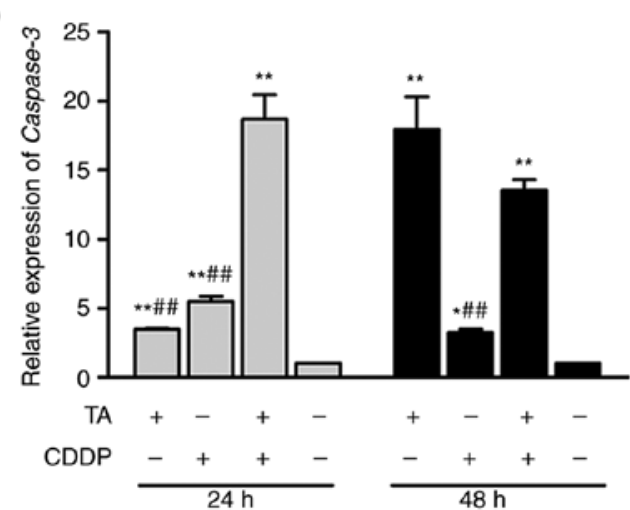

Figure 4. Combination treatment with TA and CDDP decreased the Bcl-2 mRNA expression level and increased the transcription of Bax, CytC and caspase-3. HepG2 cells were exposed to a combination of TA and CDDP for $24 \mathrm{~h}$ and (A) the mRNA level of the anti-apoptotic member Bcl-2 was significantly decreased, while the expression of (B) Bax, (C) CytC and (D) caspase-3 was significantly increased. Experiments were performed in triplicate. ${ }^{*} \mathrm{P}<0.05$ and ${ }^{* *} \mathrm{P}<0.01$ vs. the control group. ${ }^{\#} \mathrm{P}<0.05$ and ${ }^{\# \#} \mathrm{P}<0.01$ vs. the TA + CDDP group. TA, tannic acid; CDDP, cis-dichlorodiamine platinum; Bax, Bcl-2-associated $\mathrm{X}$ apoptosis regulator; CytC, cytochrome $c$. 

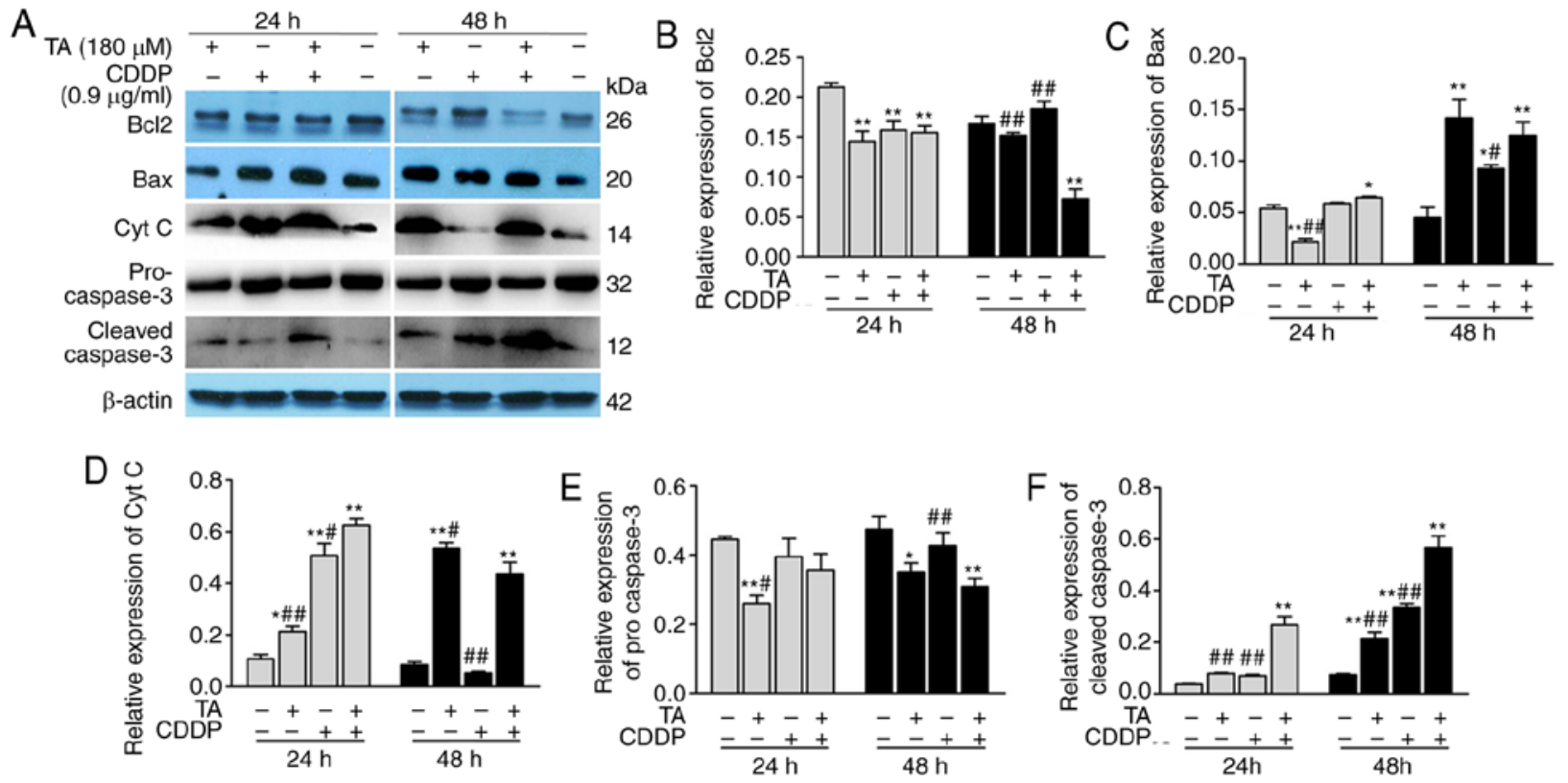

Figure 5. Combination treatment with TA and CDDP downregulated Bcl-2 and upregulated Bax, CytC and caspase-3 in HepG2 cells. HepG2 cells were exposed to a combination of TA and CDDP for 24 or $48 \mathrm{~h}$ and western blot analysis indicated that (A and B) Bcl-2 was significantly downregulated and (A and C) Bax, (A and D) CytC and (A and F) caspase-3 were significantly upregulated after $48 \mathrm{~h}$. Changes in the expression of procaspase-3 were not found to be statistically significant. Experiments were performed in triplicate. ${ }^{*} \mathrm{P}<0.05$ and ${ }^{* *} \mathrm{P}<0.01$ vs. the control group. ${ }^{~} \mathrm{P}<0.05$ and ${ }^{\# \#} \mathrm{P}<0.01$ vs. the TA $+\mathrm{CDDP}$ group. TA, tannic acid; CDDP, cis-dichlorodiamine platinum; Bax, Bcl-2-associated $\mathrm{X}$ apoptosis regulator; CytC, cytochrome $c$.
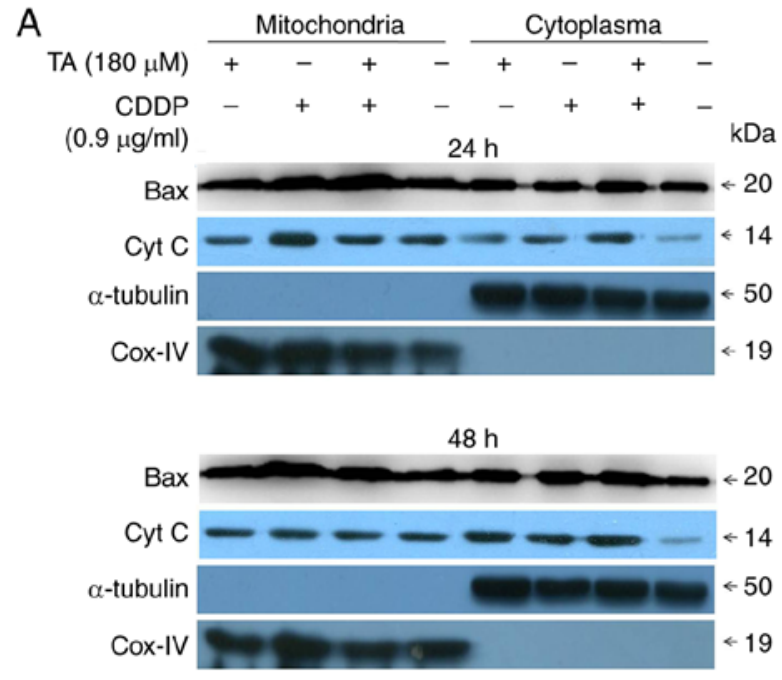

B
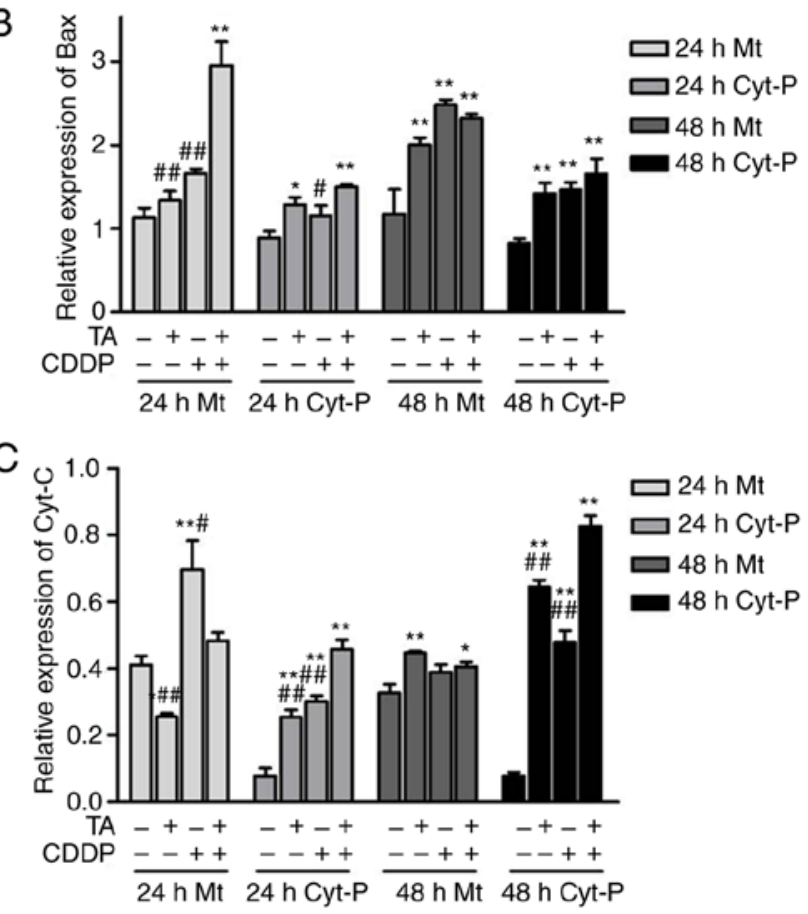

Figure 6. Combination treatment with TA and CDDP promoted the release of CytC to the cytoplasm and subsequent mitochondria-mediated apoptosis. Cells were treated with a combination of TA and CDDP for 24 or $48 \mathrm{~h}$ and mitochondria were subsequently isolated from the cytoplasm. (A and B) Bax expression and mitochondrial translocation were increased, and (A and $\mathrm{C}$ ) $\mathrm{CytC}$ concentration in the cytoplasm was significantly elevated, indicating that CytC was released from the mitochondria into the cytoplasm, thereby activating mitochondria-mediated apoptosis. Experiments were performed in triplicate. ${ }^{*} \mathrm{P}<0.05$ and ${ }^{* *} \mathrm{P}<0.01$ vs. the control group. ${ }^{\#} \mathrm{P}<0.05$ and ${ }^{\# \#} \mathrm{P}<0.01$ vs. the TA + CDDP group. TA, tannic acid; CDDP, cis-dichlorodiamine platinum; CytC, cytochrome $c$; Bax, Bcl-2-associated $\mathrm{X}$ apoptosis regulator.

\section{Discussion}

CDDP is a commonly used anticancer agent and TA has previously been reported to suppress the growth of different types of cancer cells. The present study provided novel and direct evidence that the combination of TA and CDDP synergistically inhibited the growth of the liver cancer cell line HepG2. When the drugs were used alone, the $\mathrm{IC}_{50}$ of TA and CDDP 
was $360 \mu \mathrm{M}$ and $1.8 \mu \mathrm{g} / \mathrm{ml}$, respectively. For the combination treatment, half the dose of the $\mathrm{IC}_{50}$ of each drug was used, and a significantly more prominent inhibitory effect was observed in HepG2 cells compared with the use of either drug alone.

Of note, although the HepG2 was originally considered to be a hepatocellular carcinoma (HCC) cell line, it has now been shown that it was likely derived from a hepatoblastoma (http://web.expasy.org/cellosaurus/CVCL_0027). In the present study, the growth of HepG2 cells was found to be synergistically suppressed by the combination of TA and CDDP, whereas this does not exclude the possibility that the combination of these two drugs may also be able to inhibit other types of liver cancer, such as HCC, which merits further investigation.

The results obtained in the present study indicated that exposing HepG2 cells to a combination of TA and CDDP for $24 \mathrm{~h}$ decreased the MTP and upregulated Bcl-2, Bax and CytC. Following exposure for $48 \mathrm{~h}, \mathrm{Bcl}-2$ was significantly downregulated, while Bax and $\mathrm{CytC}$ remained upregulated. These results indicate that HepG2 cells attempted to resist treatment by upregulating Bcl-2 at the early stage of apoptosis. However, continued exposure to TA and CDDP resulted in irreversible apoptosis, demonstrated by the downregulation of Bcl-2, the upregulation of Bax, the release of CytC and the activation of caspase-3. Isolation of mitochondria from the cytoplasm and subsequent western blot analysis further demonstrated that the combination of TA and CDDP promoted the release of CytC into the cytoplasm, and the translocation of Bax from the cytoplasm into the mitochondria. CytC plays an important role in mitochondria-mediated apoptosis. Under normal conditions, $\mathrm{CytC}$ is located in the inner membrane of the mitochondria and cannot pass through the outer membrane. The release of CytC is a marker of activation of mitochondria-mediated apoptosis (35). Therefore, a combination of TA and CDDP may synergistically induce the opening of the transmembrane pores, leading to enhanced permeability of the pores and decreasing the MTP. These events ultimately result in mitochondria-mediated apoptosis. Since CDDP inhibits tumor cell growth via autophagy, it is likely that TA plays a key role in mitochondria-mediated apoptosis in HepG2 liver cancer cells. Indeed, previous reports have demonstrated that TA is able to induce mitochondria-mediated apoptosis in certain types of cancer cell lines, such as the gingival cancer cell line YD-38, breast cancer cells, and the glioma cell line T98G $(23,24,36)$. Our findings in HepG2 liver cancer cells are consistent with those reports.

In addition, previous studies have revealed that CDDP in combination with other anticancer agents, such as acetazolamide, cetuximab, 5-fluorouracil and metalloproteinase 3, may enhance the chemosensitivity of cancer cells and improve survival outcomes (6-9). However, those anticancer agents are usually associated with considerable toxic side effects. The findings of the present study demonstrated that TA was able to synergistically enhance the anticancer effect of CDDP, even at their respective half $\mathrm{IC}_{50}$ values (TA, $180 \mu \mathrm{M}$; CDDP, $0.9 \mu \mathrm{g} / \mathrm{ml}$ ). The combined inhibition rate was 3 -fold higher compared with that by CDDP alone. Since TA is a natural plant polyphenol and has been widely used as a dietary supplement, its favorable toxicity profile makes it superior to other anticancer agents.

In conclusion, the present study revealed that a combination of TA and CDDP significantly increased the anticancer effect on HepG2 cells compared with either drug alone, which may substantially decrease the toxicity to normal cells. These results provide novel insights into targeted chemotherapy for liver cancer.

\section{Acknowledgements}

The authors are grateful to Professor Zhimin Zhang and Dr Youfu Pan at Zunyi Medical University for their advice.

\section{Funding}

The present study was supported by the National Natural Science Foundation of China (grant no. 81760508), the Natural Science Foundation of Guizhou Province [grant no. LH (2014)7548], the Creative Team of Special Drug in Education Office of Guizhou Province [grant no. (2013)15] and the Master's Scientific Fund of Zunyi Medical University (grant nos. F-841 and F-827).

\section{Availability of data and materials}

All the datasets generated and analyzed in the present study are included in this published article.

\section{Authors' contributions}

XL, MW and JC designed the study, analyzed the data and wrote the manuscript. NG and XZ performed most of the experiments such as cell culture, cell viability assay cell morphological analysis, apoptosis assay, RT-PCR and western blot analysis. LY participated in some of the western blotting experiments. All authors read and approved the final manuscript.

\section{Ethics approval and consent to participate}

Not applicable.

\section{Patient consent for publication}

Not applicable.

\section{Competing interests}

The authors declare that they have no competing interests.

\section{References}

1. Ferrin G, Aguilar-Melero P, Rodriguez-Peralvarez M, Montero-Alvarez JL and de la Mata M: Biomarkers for hepatocellular carcinoma: Diagnostic and therapeutic utility. Hepat Med 7: 1-10, 2015

2. Proença de Moraes T, Massignan B, Figueiredo AE, Barretti P, Olandoski M, Kirk A and Pecoits-Filho R: Systemic lupus erythematous and clinical outcomes in peritoneal dialysis. Lupus 24: 290-298, 2015.

3. Torre LA, Bray F, Siegel RL, Ferlay J, Lortet-Tieulent J and Jemal A: Global cancer statistics, 2012. CA Cancer J Clin 65: 87-108, 2015

4. Ferlay J, Soerjomataram I, Dikshit R, Eser S, Mathers C, Rebelo M, Parkin DM, Forman D and Bray F: Cancer incidence and mortality worldwide: Sources, methods and major patterns in GLOBOCAN 2012. Int J Cancer 136: E359-E386, 2015. 
5. Chen W, Zheng R, Baade PD, Zhang S, Zeng H, Bray F, Jemal A Yu XQ and He J: Cancer statistics in China, 2015. CA Cancer J Clin 66: 115-132, 2016.

6. Gao H, Dong H, Li G and Jin H: Combined treatment with acetazolamide and cisplatin enhances chemosensitivity in laryngeal carcinoma Hep-2 cells. Oncol Lett 15: 9299-9306, 2018.

7. Peng F, Zhang H, Du Y and Tan P: Cetuximab enhances cisplatin-induced endoplasmic reticulum stress-associated apoptosis in laryngeal squamous cell carcinoma cells by inhibiting expression of TXNDC5. Mol Med Rep 17: 4767-4776, 2018.

8. Hoch MA, Cousins K, Nartey R, Riley K and Hartranft M: Two cases of combination therapy with cetuximab, paclitaxel, and cisplatin for advanced head and neck cancer. J Oncol Pharm Pract 24: 553-554, 2018

9. Shen X, Gao X, Li H, Gu Y and Wang J: TIMP-3 increases the chemosensitivity of laryngeal carcinoma to cisplatin via facilitating mitochondria-dependent apoptosis. Oncol Res 27: 73-80, 2018.

10. Manohar S and Leung N: Cisplatin nephrotoxicity: A review of the literature. J Nephrol 31: 15-25, 2018.

11. Paken J,Govender CD,Pillay Mand Sewram V:Cisplatin-associated ototoxicity: A review for the health professional. J Toxicol 2016 : 1809394, 2016

12. Barabas K, Milner R, Lurie D and Adin C: Cisplatin: A review of toxicities and therapeutic applications. Vet Comp Oncol 6: 1-18, 2008.

13. Palmieri A, Iapichino A, Cura F, Scapoli L, Carinci F, Mandrone $\mathrm{M}$ and Martinelli $\mathrm{M}$ : Pre-treatment with berberine enhances effect of 5-fluorouracil and cisplatin in HEP2 laryngeal cancer cell line. J Biol Regul Homeost Agents 32 (Suppl 1): S167-S177, 2018.

14. Matoba T, Ijichi K, Yanagi T, Kabaya K, Kawakita D, Beppu S, Torii J and Murakami S: Chemo-selection with docetaxel, cisplatin and 5-fluorouracil (TPF) regimen followed by radiation therapy or surgery for pharyngeal and laryngeal carcinoma. Jpn J Clin Oncol 47: 1031-1037, 2017.

15. Lohitesh K, Chowdhury R and Mukherjee S: Resistance a major hindrance to chemotherapy in hepatocellular carcinoma: An insight. Cancer Cell Int 18: 44, 2018

16. Ryu SH and Chung YH: How to overcome multidrug resistance in chemotherapy for advanced hepatocellular carcinoma. Liver Int 30: 496-498, 2010.

17. Sun Y, Zhang T, Wang B, Li H and Li P: Tannic acid, an inhibitor of poly(ADP-ribose) glycohydrolase, sensitizes ovarian carcinoma cells to cisplatin. Anticancer Drugs 23: 979-990, 2012.

18. Booth BW, Inskeep BD, Shah H, Park JP, Hay EJ and Burg KJ: Tannic Acid preferentially targets estrogen receptor-positive breast cancer. Int J Breast Cancer 2013: 369609, 2013.

19. Tikoo K, Sane MS and Gupta C: Tannic acid ameliorates doxorubicin-induced cardiotoxicity and potentiates its anticancer activity: Potential role of tannins in cancer chemotherapy. Toxicol Appl Pharmacol 251: 191-200, 2011.

20. Cass CA and Burg KJ: Tannic acid cross-linked collagen scaffolds and their anticancer potential in a tissue engineered breast implant. J Biomater Sci Polym Ed 23: 281-298, 2012.

21. Chen KS, Hsiao YC, Kuo DY, Chou MC, Chu SC, Hsieh YS and Lin TH: Tannic acid-induced apoptosis and -enhanced sensitivity to arsenic trioxide in human leukemia HL-60 cells. Leuk Res 33 : 297-307, 2009
22. Cosan D, Soyocak A, Basaran A, Degirmenci I and Gunes HV: The effects of resveratrol and tannic acid on apoptosis in colon adenocarcinoma cell line. Saudi Med J 30: 191-195, 2009.

23. Darvin P, Baeg SJ, Joung YH, Sp N, Kang DY, Byun HJ, Park JU and Yang YM: Tannic acid inhibits the Jak2/STAT3 pathway and induces G1/S arrest and mitochondrial apoptosis in YD-38 gingival cancer cells. Int J Oncol 47: 1111-1120, 2015.

24. Darvin P, Joung YH, Kang DY, Sp N, Byun HJ, Hwang TS, Sasidharakurup $\mathrm{H}$, Lee $\mathrm{CH}$, Cho KH, Park KD, et al: Tannic acid inhibits EGFR/STAT1/3 and enhances p38/STAT1 signalling axis in breast cancer cells. J Cell Mol Med 21: 720-734, 2017.

25. Kamei H, Koide T, Hashimoto Y, Kojima T and Hasegawa M: Tumor cell growth suppression by tannic acid. Cancer Biother Radiopharm 14: 135-138, 1999.

26. Karakurt $\mathrm{S}$ and Adali $\mathrm{O}$ : Tannic acid inhibits proliferation, migration, invasion of prostate cancer and modulates drug metabolizing and antioxidant enzymes. Anticancer Agents Med Chem 16: 781-789, 2016.

27. Majed F, Rashid S, Khan AQ, Nafees S, Ali N, Ali R, Khan R, Hasan SK, Mehdi SJ and Sultana S: Tannic acid mitigates the DMBA/croton oil-induced skin cancer progression in mice. Mol Cell Biochem 399: 217-228, 2015.

28. Nagesh PKB, Hatami E, Chowdhury P, Kashyap VK, Khan S, Hafeez BB, Chauhan SC, Jaggi M and Yallapu MM: Tannic acid induces endoplasmic reticulum stress-mediated apoptosis in prostate cancer. Cancers (Basel) 10: E68, 2018.

29. Naus PJ, Henson R, Bleeker G, Wehbe H, Meng F and Patel T: Tannic acid synergizes the cytotoxicity of chemotherapeutic drugs in human cholangiocarcinoma by modulating drug efflux pathways. J Hepatol 46: 222-229, 2007.

30. Ngobili TA, Shah H, Park JP, Kwist KW, Inskeep B, Burg KJ and Booth BW: Remodeling of tannic acid crosslinked collagen type I induces apoptosis in $\mathrm{ER}^{+}$breast cancer cells. Anticancer Res 35 : $1285-1290,2015$

31. Nie F, Liang Y, Jiang B, Li X, Xun H, He W, Lau HT and Ma X: Apoptotic effect of tannic acid on fatty acid synthase over-expressed human breast cancer cells. Tumour Biol 37: 2137-2143, 2016

32. Zhang J, Chen D, Han DM, Cheng YH, Dai C, Wu XJ, Che FY and Heng XY: Tannic acid mediated induction of apoptosis in human glioma Hs 683 cells. Oncol Lett 15: 6845-6850, 2018.

33. Livak KJ and Schmittgen TD: Analysis of relative gene expression data using real-time quantitative PCR and the 2(-Delta Delta C(T)) method. Methods 25: 402-408, 2001

34. Loewe S: The problem of synergism and antagonism of combined drugs. Arzneimittelforschung 3: 285-290, 1953.

35. Estaquier J, Vallette F, Vayssiere JL and Mignotte B: The mitochondrial pathways of apoptosis. Adv Exp Med Biol 942: 157-183, 2012.

36. Zielińska-Przyjemska M, Kaczmarek M, Krajka-Kuźniak V, Łuczak M and Baer-Dubowska W: The effect of resveratrol, its naturally occurring derivatives and tannic acid on the induction of cell cycle arrest and apoptosis in rat C6 and human T98G glioma cell lines. Toxicol In Vitro 43: 69-75, 2017. 